\title{
The Development of Diagnostic Test Instrument Based Online Multimedia to Describe Students Difficulties in Integer and Fraction Operation
}

\author{
Suciati \\ Universitas Borneo Tarakan \\ Tarakan, Indonesia \\ Cauchy_my@yahoo.com
}

\begin{abstract}
The purpose of this study was to develop a diagnostic test of students' difficulties in the matter of integer and fraction operations through the approach of strength and weakness profiles. The instrument was developed using test development procedures consisting of (1) preparing the test specification, (2), writing the test, (3) reviewing the test, (4) implementing the test trial, (5) analyzing the test items, (6) improving the test, (7) assembling the test, (8) implementing the test, and (9) interpreting the test. The subject of this research is 47 students of junior high school grade 7 in Tarakan City. The result showed that the developed diagnostic test fulfills the valid criteria based on Aiken index; it obtained 0.80 with a reliability coefficient of 0.749 . From 13 items developed, there are 10 items that are feasible and valid to be used. Item discrimination index of items test developed is in the range of 0.30 to 0.5 and items difficulty index is in the range of 0.30 to 0.70 . The result of the implementation indicates that the test is able to describe students' difficulties in the matter of integer and fraction operations.
\end{abstract}

\section{Keywords - diagnostic tests, integer and fraction operations}

\section{INTRODUCTION}

One of the subjects tested in the national examination is mathematics. It is a universal science that supports the development of modern technology. It has an important role in various disciplines and advances the human mind. As one means of scientific thinking, mathematics is needed to increase students' ability to think logically, systematically and critically. It is so reasonable if the government makes mathematics as one of the compulsory subjects for students in elementary and secondary education levels. This is explicitly stated in the law of Indonesia number 20 the year 2003 which is about National Education System in Chapter II Article 37.

As a basic knowledge, mathematics is needed by students to support their learning success in higher education level. In fact, it plays a role in improving the quality of human resources and it is also a tool to develop other disciplines. Mathematics education has a very important role in facing the global era. As a compulsory subject in every level of educations, there are several competencies that are expected to be owned by students.

Mathematics is very important in life [1] such as in some occupations, science and technology, medicine, economics, government and others. Mathematics is not a solitary knowledge that can be perfect because of itself, but its existence is to help human beings in understanding and mastering social, economic and natural problems.

Mathematics is given to all students starting from elementary school, in order to equip learners with logical, analytical, systematic, critical and creative thinking and ability to work together. This is in line with the objectives of mathematics learning that include: 1). understanding the concept of mathematics, explaining the interconnections between concepts and applying the concepts or explaining algorithms flexibly, accurately, efficiently and correctly in problem solving; 2). Using intellection on patterns and traits; 3). Problems Solving that include the ability to understand problems, mathematical design models, complete models and interpret the solutions obtained; 4). Communicating ideas with symbols, tables, diagrams or other media to clarify the problems; 5). Acquiring an appreciative attitude of the usefulness of mathematics in life [2].

In the education field, the mastery of mathematics matter for the students will be a powerful tool in studying other sciences, either at the same level of education or at higher levels. However, mathematics is still regarded as the most difficult lesson by children and adults.

The achievement of mathematics learning objectives can be judged by the students' success in understanding mathematics and utilizing the understanding to solve mathematical questions. Based on the last 2 years data of junior high school national examination in Tarakan, the average score is still in the lowest position compared to the other subjects tested, the average score has not been satisfying, because it has not reached the minimum graduation score requirement which is 5.50. The low average score indicates that the students of junior high school in Tarakan have difficulty in solving the mathematics questions which are related to the initial matter in grade 7 .

Based on the result of Absorption test of junior high school national examination questions, the mastery of number operation, social arithmetic, and sequence or series matters is the lowest compared with other matters. The student's mistakes in answering the national examination questions indicate that the students have difficulty in solving or 
answering questions related to the matters. Number operation is the first mathematics matter that must be studied by grade 7 students in semester 1. This is based on the syllabus of junior high school grade 7 Semester 1 Curriculum 2013 which covers numbers operation, sets, equations and inequalities linear of one variable, proportion, social arithmetic, and number pattern. In this case, it can be concluded that number operation is an initial subject matter which is very important to be mastered by students. If they have not been able to master it, then they will have difficulties in taking the next subject matters, because the number operation is the prerequisite to take them.

In relation to the statement above, it can be concluded that the indication of junior high school students in Tarakan has difficulties in solving the mathematical problems related to the number operation matter is because of a special factor. So, the indication causes mathematics learning achievement that related to it low. Then, it also gives negative effects to the next matters achievement. If students' difficulties in solving math problems are left unchecked, then the students' learning achievement cannot be achieved properly. Therefore, the teacher must have the ability to identify students' difficulties in solving math problems, especially the matter of number operations. It means that the teachers are not only required to analyze the subject matters that will be delivered but also various difficulties experienced by students in receiving the lesson delivered. Through this identification, teachers can know what kind of difficulties students are experiencing in solving mathematical problems which are related to number operations.

In order to make teachers able to identify students' difficulties in the matter of number operations, so an instrument that can assist them in diagnosing students' difficulties is needed. Then, it is necessary to develop a valid and reliable measuring instrument that can diagnose students difficulties in the form of diagnostic test towards number operations matter.

\section{METHOD}

This research was developmental research in the field of education. The development procedure used was procedural development based on the test development procedures, the procedures were: (1) Preparing the test specification, (2), Writing the test, (3) Reviewing the test, (4) conducting the test trial, (5) Analyzing the test items, (6) improving the test, (7) assembling the test, (8) carrying out the test, and (9) interpreting the test [3].

The subjects of this research were 47 junior high school students in Tarakan. The data collection techniques used in this research were: (1) walking through, it performs on 3 expert review stage to get validity in the aspects of content, construct, language, and multimedia of the test; (2) the tests are given to students via Google form by loading text, images, and video.

Data analysis technique used in this research was a descriptive analysis which consists of two stages, which are the stage of instrument preparation, and the stage of test results analysis. In the stage of content validity test, the instrument developed had been validated by 3 experts. The experts were given latticework and instrument items. The experts were asked to provide feedbacks related to the instrument items and filled out the validation sheets which are about the conformity of the items with the indicators. The assessment was done by giving a number between 1 (very unrepresented or highly irrelevant) to 5 (highly relevant). Formula Aiken was formulated, as follows [4].

$$
V=\sum s /[n(c-1)]
$$

In order to know the quality of the test items developed, the data of the trial result which is in the form of subject response patterns were analyzed using criteria in table 1 below:

TABLE I. SELECTION CRITERIA OF MUlTIPLE CHOICE QUESTIONS

\begin{tabular}{|l|l|l|}
\hline \multicolumn{1}{|c|}{ Criteria } & \multicolumn{1}{|c|}{ Coefficient } & \multicolumn{1}{c|}{ Conclusion } \\
\hline & $>0.90$ (very easy) & Rejected \\
& 70 s/d 0.90 (easy) & Revised \\
difficulty level & $0.30 \mathrm{~s} / \mathrm{d} 0.70$ (medium) & Accepted \\
& $0.10 \mathrm{~s} / \mathrm{d} 0.290$ (easy) & Revised \\
& $<0.10$ (very difficult) & Rejected \\
\hline & $0.40-1.00$ & $\begin{array}{l}\text { Questions accepted well } \\
\text { Questions accepted, but } \\
\text { need to be revised }\end{array}$ \\
Discriminating & $0.30-0.39$ & Questions revised \\
power & & Questions rejected \\
& $0.20-0.29$ & \\
\hline $\begin{array}{l}\text { Answers } \\
\text { proportion }\end{array}$ & $0.00-0.19$ & Work well \\
& $>0.05$ & \\
\hline
\end{tabular}

\section{RESULT AND DISCUSSION}

\section{A. Preparing test specifications}

The preparation of test specifications begins with setting the objectives of the test that will be developed, arranging the test lattice, determining the test form, and determining the length of the test. Based on the analysis result, the developed instrument aims to diagnose students' difficulties in the matter of integer and fractional operations. Based on the results of the syllabus analysis, the competence standard used is to compare and sort various types of numbers, and also to apply integer and fraction operation by utilizing its various properties. The instrument latticework is developed by examining the syllabus, so the draft indicators are obtained. It consists of 4 indicators with the form of the test that will be developed, and it is multiple choices with 13 items test length.

\section{B. Writing the test}

At this stage, the researcher begins to write a test regarding the rules of writing a multiple choice test. The indicators are developed into test items referring to the instrument of latticework. Each indicator is developed into 3 test items and 1 indicator becomes 4 test items. The test items developed are 13 items with 5 deceptions. 


\section{Reviewing the test}

The next stage is to review the test items developed. The review of the test items is done using the test preparation guideline. The test items that have been written are reviewed for their appropriateness to the concepts, writing technique, and language used. Based on the review result, there are 10 items that fulfill the criteria and 3 items that do not fulfill it. Furthermore, 3 test items that have not fulfilled the criteria are improved.

\section{Implementing the test trial}

Test trial is conducted to obtain empirical data which are about the reliability, validity, response patterns of the test participants and others. Test trial is conducted with expert judgments and development test. The trial is conducted on the test items and the display of the developed online multimedia. The trial of the online multimedia display is conducted by providing the student's assessment sheets in order to assess the display of the developed diagnostic tests which is online-based multimedia.

\section{E. Trial with Expert Judgment}

The instrument which has been developed is validated by 3 experts to obtain data about the content validity. The experts are given latticework and instrument items. The experts are asked to provide feedbacks on instrument items and fill out the validation sheets about the conformity of the items with the indicators. Assessment is done by giving a number between 1 (very unrepresented or highly irrelevant) to 5 (highly relevant). After that, determining the calculation of the content validity based on the expert's agreement using Aiken index. The result of content validity calculation which is based on the expert's agreement on construction, language, and content aspect is presented in table 2 below.

TABLE II. THE RESULT OF THE CONTENT VALIDATION FEASIBILITY ANALYSIS

\begin{tabular}{|l|l|l|l|c|}
\hline \multicolumn{1}{|c|}{ Aspects } & Minimum & Maximum & Average & SD \\
\hline Construction & 0.75 & 0.90 & 0.80 & 0.06 \\
\hline Language & 0.77 & 0.85 & 0.79 & 0.05 \\
\hline Content & 0.75 & 0.93 & 0.80 & 0.06 \\
\hline
\end{tabular}

By observing table 2, it appears that the result of the content validity of the developed instrument shows that the whole instrument has a value from 0.75 to 0.93 with an average of 0.80 . It means that it has good content validity and supports the test content validity wholly. In addition, revisions are made based on the suggestions from the experts related to the grammar, selection of deception, layout of the item test order, conformity of the indicators with the instrument components, images selection and appropriate videos.

\section{F. Development Test}

The development test is conducted through test trial developed in the real class and students to obtain revised sections based on the findings that show up during the trial. The development test is conducted to the seventh grade of junior high school students in Tarakan by asking the help of math teacher to share the URL link from Google form developed. The students are asked to answer the questions according to the allocation determined in the school computer laboratory.

Based on the result of the trial, the student's response pattern towards 13 test items developed is found. Then, the response pattern is analyzed to determine the reliability coefficient and the quality of the test items developed.

The reliability coefficient of this test can be seen from the value of the alpha coefficient. The ITEMAN analysis result shows that the alpha coefficient is 0.749 . If the conventional benchmark is used as a test reliability criteria and it is set to $r>0.70$, then it can be concluded that the test instrument is reliable or its reliability is in a good category, because the value of alpha coefficient $(0.749)$ is greater than 0.70 .

\section{G. Analyzing the test items}

After the trial has been done, information related to the test quality that is developed will be obtained. Based on the analysis result of the questions items related to integer and fractional operations matters which include the discriminating power, difficulty level, and functionality of the distractor, so the rejected and feasible items with revision are obtained. The difficulty levels of the items range from 0.30 to 0.70 . It means that the items developed are sufficient, so they are acceptable or they can be used. The discriminating power of the test items developed is in the range of $0.30-0.5$. The discriminating power, r_ (bis), and both of r_pbis are marked positive. It indicates that the questions can differentiate the ability of test participants. The smart test takers tend to answer them correctly, but less smart test takers tend to answer them incorrectly. By having a look at the discriminating power of each deception, it can also be concluded that it is good, because r_ (bis) and r_pbis for alternative answers, except correct answers on each test items are all negative, it indicates that smart test takers will not choose the alternative answers, whereas less smart test takers tend to do it. In other words, the test takers whose lower scores choose the deception as the correct answer.

Reviewing the answers distribution which is the percentage of test participants choosing the alternative answers, it seems that some of the deceptions have functioned well $(>0.050)$. It means that there are the items which are accepted or can be used without revision, and there are also items that can be used but with revisions.

From 13 diagnostic test items developed in the early stages, after the trial has been done, 10 items are obtained, and they are considered good and can be used in terms of the difficulty level and discriminating power.

\section{H. Improving the test}

Based on the result of trial and test item analysis, it will get good and not good test item information, and test items that have not fulfilled the criteria or are not well corrected. In addition, revisions are made based on the suggestions from the experts related to the grammar, selection of deception, layout 
of the test items, compatibility of the indicators with the instrument components and others.

\section{Assembling the test}

After an improvement has been made to the test items which have not been good based on the results of the trial and term analysis, the next step is to assemble the test items into an entity. The entire items are assembled by paying attention to the order of difficulty level, display, readability and others.

\section{J. Implementing the test}

The test items that have been assembled into an entity, they are used to implement the test. The test items are given to the test participants, who are the students of junior high school grade VII. At this stage, the test participants are different from the previous ones. The Implementation of the test is done in accordance with the allocated time which is 30 minutes.

\section{$K$. Interpreting the test}

The last part of the design development and implementation phase is interpreting the test. The interpretation of the test is based on the score obtained by the test participants. The scoring process is done based on the developed scoring guideline.

\section{CONCLUSION}

From the results, it can be concluded that the instrument test is able to describe students' difficulties in the matter of integer and fraction operations. The reliability coefficient of the instrument test developed is 0.749 , the content validity shows 0.80 . From 13 items developed, there are 10 items worth using.

\section{ACKNOWLEDGMENT}

The author would like to thank the Indonesia Endowment Fund For Education (LPDP) for their support on his study.

\section{REFERENCES}

[1] D. Haylock and Fiona Thangata, Key concepts: Teaching primary mathematics. London: Sage Publications Ltd, 2007.

[2] S. Wardhani, Impilakasi Karakteristik Matematika dalam Pencapaian Tujuan Mata Pelajaran Matematika SMP/MTS. Yogyakarta: Departemen Pendidikan Nasional Direktorat Jenderal Peningkatan Mutu Pendidik dan Tenaga Kependidikan Pusat Pengembangan dan Pemberdayaan Pendidik dan Tenaga Kependidikan (PPPPTK) Matematika, 2010.

[3] D. Mardhapi, Pengukuran, Penilaian, dan evaluasi Pendidikan. Yogyakarta: Parama Publishing, 2017.

[4] L. Aiken, Three Coefficients For Analyzing The Reliability And Validity Of Ratings. Psychological testing and assessment. Sexta edición. Boston: Allyn and Bacon, Inc, 1985. 